\title{
Cell-culture Database: Literature-based reference tool for human and mammalian experimentally- based cell culture applications
}

\author{
Vafa Amirkia* \& Pan Qiubao
}

TOKU-E Company, 150 Cecil St. \#16-00, Singapore - 069543; Vafa Amirkia - Email: vamirkia@toku-e.com; Phone: +86-21-57662059; Fax: +86-21-5766-5447; *Corresponding author

Received March 05, 2012; Accepted March 07, 2012; Published March 17, 2012

\begin{abstract}
:
Cultivation of primary cells is essential for biotechnological research and viral vaccine production. Significant advances in cell and tissue culture, more specifically, advances in the transfection and transduction of human and mammalian cells, has directly led to giant leaps forward in fields such as cancer research, genetics, and public health. At the same time, a corresponding increase has been seen in available cell culture related literature. Often times, due to the sheer number and degree of variability of available literature, it is a challenge to find specific, yet practical cell culture related information.

To respond to this rising tide of information, a practical, user-friendly database containing cell-lines, plasmids, vectors, selection agents, concentrations and media was created. The database currently consists of over 3,900 cell lines (Human and Mammalian) and 1,900 plasmids/vectors collected from 2,700 pieces of published literature. The database is continually being expanded and it is hoped that through the continual addition of unique data, the database can further serve and enrich the work of cell and molecular biologists, life-science professionals, and the worldwide scientific community at large.
\end{abstract}

Availability: http://cell-lines.toku-e.com/

\section{Background:}

Cell culture is a highly controlled, fragile and complex setting for scientific research. In order to successfully transfect cells, several variables such as nutrient levels, temperatures, reagent concentrations, media, and most importantly - time, must all carefully be balanced. With the proliferation of cell line sources and strains, plasmids, media, selection agents and growth conditions in recent decades it has become increasingly difficult to quickly analyze large samples of data related to transfection of a particular cell line against a specific plasmid.

It is well known that cells for various reasons often times refuse to grow or be transfected. Sometimes irregularities can be attributed to problems in media, cultivation conditions, or a sudden Mycoplasma infection while other times the cause is unknown [1]. Some these irregularities can originate from external factors such as cell line contamination (since 2000, estimates of cross contamination of cell lines have increased sharply), while others are a result of incorrect experimental practices [2]. Often time's frustration arises when of set of experimental conditions from another paper or protocol is strictly followed, but leads to non-growth of cells. Questions which naturally arise from these challenges relate to how variations in materials and methods (ex. media, selection agent, concentration, etc.) can be made without adversely affecting the cultured cells. Through the presentation of large datasets, the Cell-culture Database seeks to alleviate some of the aforementioned challenges and provide a comprehensive and reliable resource for those who frequently transfect cells. 


\section{Methodology:}

\section{Construction of the Database}

The several thousand papers in the database originate from over 100 journals including: The Journal of Biological Chemistry, Brain Research, Diagnostic Microbiology and Infectious Disease, Journal of Virology, Journal of Physical Chemistry, etc. Google scholar was utilized for harvesting papers and EndNote was used to organize and publish references $[3,4]$. The electronic, web-based version of the database is written in C\# and can be accessed at http://celllines.toku-e.com /.

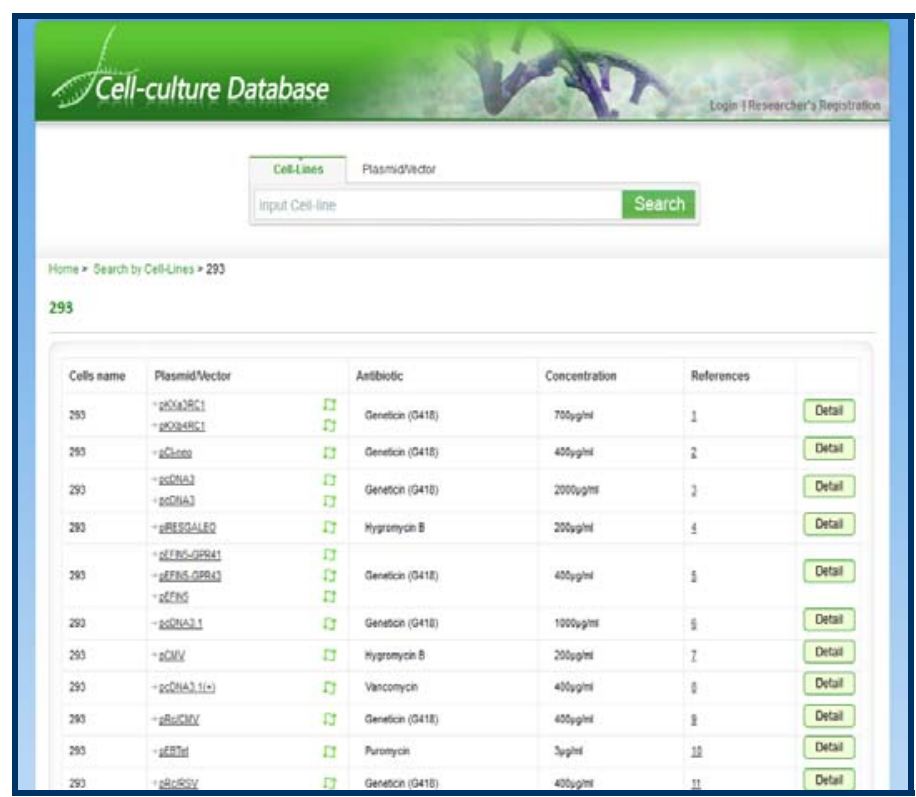

Figure 1: A screenshot of the Cell-culture Database

\section{Features}

The Cell-culture Database currently consists of over 3,900 cell lines (Human and Mammalian) and 1,900 plasmids/vectors collected from 2,700 pieces of published literature. Furthermore, details related to experimental conditions such as cultivation temperature and time has also been noted. The dataset can be searched either by cell-line or by plasmid/vector. Once a particular cell line and plasmid of interest (eg. 293 cells and pcDNA3) have been located, a deeper, more specific search isolating only this one cell line and one plasmid can be performed. Such specific data can quickly provide alternate selection reagents/concentrations, media, and growth conditions for those who have encountered problems in their cell culture. Although some of these features are commonly found in other cell culture related literature, others remain unique to the database [5]. References for all data are also published for future investigation and research (Figure 1).

\section{Utility to the Greater Biological Community:}

The Cell-culture Database is a reference tool designed to primarily serve and enrich the work of cell and molecular biologists, and life-science professionals. The datasets contained allow for the user to confirm the use of appropriate selection agents and concentrations. At the same time, users can switch to an entirely new set of media and/or selection agents from the displayed alternatives encompassed therein. Cultivation conditions can also be adjusted based on alternates displayed in the database. Although some books and other resources have attempted to offer suggestions for alternate methods, large databases related to particular cell-line and/or plasmids are not available. The database not only seeks to allow users to confirm their experimental protocols, but also seeks to solve some of the aforementioned uncertainties in cell culture through logical presentation of additional culturing methods.

\section{Future Directions:}

The accuracy and breadth of the Cell-culture database is continuously being improved upon. Plans to steadily and significantly expand content with additional cell lines and plasmids are already underway. At its core, the database is most closely related to transfection of primary cells and does not aim to be a highly technical resource like other databases [6]. Already, the online version of the database has received several thousands of visitors in its first few months. With the addition of increased unique data and functionality, this trend is expected to increase in the coming months and years.

\section{References:}

[1] Hay RJ et al. Nature. 1989 339: 487. [PMID: 2725683]

[2] Cabrera CM et al. Cytotechnology. 2006 51: 45 [PMID: 19002894]

[3] www.scholar.google.com

[4] www.endnote.com

[5] Mather JP \& Barnes D, Animal cell culture methods: methods in cell biology, London: Academic Press. 1998 vol. 57.

[6] Romano P et al. Nucleic Acids Research. 2009 37: D925 [PMID: 18927105]
Edited by $P$ Kangueane

Citation: Amirkia \& Qiubao, Bioinformation 8(5): 237-238 (2012) License statement: This is an open-access article, which permits unrestricted use, distribution, and reproduction in any medium, for non-commercial purposes, provided the original author and source are credited. 